\title{
A INTEGRAÇÃO REGIONAL SUL-AMERICANA: UM ESTUDO DO VIÉS SOCIAL E DA PARTICIPAÇÃO POPULAR NO MERCOSUL E NA UNASUL
}

\author{
Jamile Bergamaschine Mata Diz ${ }^{1}$ \\ Joaner Campello de Oliveira Junior²
}

RESUMO: A dimensão social da integração regional deve ser examinada, também, sob o aspecto institucional e normativo. Assim, o objetivo deste trabalho é verificar em que medida, na integração sul-americana, notadamente no Mercosul e na UNASUL, pode-se detectar a criação de instâncias destinadas a fomentar essa dimensão pautada no diálogo permanente com a sociedade civil. Busca-se, ainda, identificar os principais instrumentos normativos sobre o tema, investigando como a participação popular ocorreu no momento da tomada de decisão. Utilizaram-se os métodos histórico e dedutivo e, finalmente, conclui-se que os processos de integração representam um meio efetivo de participação cidadã, ainda que limitado.

Palavras-chaves: Dimensão Social; Integração Regional; MERCOSUL; UNASUL

\section{SOUTH AMERICAN REGIONAL INTEGRATION: A STUDY OF SOCIAL ASPECT AND POPULAR PARTICIPATION IN MERCOSUR AND UNASUR}

\begin{abstract}
The social dimension of regional integration must also be examined in institutional and policy terms. The objective of this study is to verify, in South American integration, notably in Mercosur and UNASUR, it is possible to detect the creation of instances to promote this dimension based on permanent dialogue with civil society. It also seeks to identify the main normative instruments on the subject, investigating how popular participation occurred at the moment of decision making. The historical and deductive methods were used, and finally, it is concluded that the integration processes represent an effective means of citizen participation, although limited.
\end{abstract}

Keywords: Social Dimensión; Regional Integration; MERCOSUR; UNASUR

\footnotetext{
1 Cátedra Jean Monnet Direito UFMG (coordenadora). Professora da Faculdade de Direito da UFMG. Coordenadora do PPGD da Universidade de Itaúna. Doutora em Direito Comunitário - Universidad de Alcalá. Email: jmatadiz@yahoo.com.br.

${ }^{2}$ Advogado. Pós-Graduado em Direito Público e Tributário pela AVM Educacional. Mestre em Direito das Relações Internacionais e da Integração Latino Americana pela Universidad de la Empresa - Uruguai. E-mail: joanercampello@hotmail.com.
} 


\section{INTRODUÇÃO}

$\mathrm{Na}$ atualidade, escuta-se com frequência notícias sobre a integração de diferentes atores internacionais ou sobre processos de integração. No entanto, o termo integração regional, devido à sua difusão e propagação, tem sido utilizado em diferentes e variados sentidos, a revelar polissemia que ora é afastada a favor de um significado preciso, próprio e satisfatório para o quadro em que inserida a análise da dimensão social que cerca os processos de integração da região sul-americana, notadamente o Mercosul (Mercado Comum do Sul) e a UNASUL (União das Nações Sul-americanas).

A priori, definir integração regional não deveria ser uma tarefa árdua que exigisse grande esforço, pois, em sentido denotativo, a definição de integração não se traduz em um conceito de difícil apreensão ou compreensão. Porto e Flôres Jr. (2006) afirmam que a palavra se origina do latim "integratio", significando renovação, restabelecimento. Na doutrina, todavia, esta terminologia é utilizada em sentido conotativo para explicar um fenômeno mais complexo, com distintos matizes, e, embora os estudiosos venham a definindo em âmbito regional, seus esforços não culminaram numa interpretação ou abordagem capaz de estabelecer uma conceituação comum e uniforme.

Vale lembrar que, do ponto de vista histórico, a formação de alianças e blocos entre Estados soberanos não é algo recente ou contemporâneo. As uniões entre países, ou melhor, Estados vizinhos ou separados geograficamente, mas vinculados por interesses comuns, nascem por meio dos acordos de amizade e defesa mútua para a prosperidade e segurança das nações envolvidas, assim como para protegê-las de inimigos potenciais. São exemplos de uniões com o objetivo de segurança estratégica, em distintos períodos históricos: a Liga Ateniense, a Organização do Tratado do Atlântico Norte (OTAN), a Comunidade Europeia de Defesa e, posteriormente, a integração europeia e sul-americana.

E, levando-se em consideração não apenas esse histórico integracionista, mas também a conjuntura contemporânea dos seus desdobramentos, revela-se necessário, para os dias atuais, a busca de uma nova forma de compreensão sobre tais processos, capaz de abarcá-lo dentro de uma concepção globalizada de mundo, segundo uma conceituação que não prescinda, inclusive, de uma governança concertada e da coesão social, como elementos intrínsecos da própria definição de integração, que pode ser entendida, como um produto de diversas e variadas forças, sendo uma ligação interestatal de natureza econômica, política, social e jurídica, sempre baseada na vontade de seus membros. 
O presente estudo busca analisar a integração regional sob o viés social, a partir dos sistemas institucionais e jurídicos do MERCOSUL e da UNASUL que delimitaram e desenvolveram tal viés, de modo a incrementar a participação popular, e fortalecer, assim, os valores democráticos na região. Neste sentido, examinou-se em que medida estes sistemas contam com a estrutura específica voltada para o atendimento das premissas vinculadas à participação, concretizando a dimensão social dos processos de integração sub-regionais. $\mathrm{O}$ recorte adotado no presente trabalho deu-se mediante uma análise espacial, vez que destinado a analisar os processos integracionistas da América do Sul nos quais o Brasil participa como membro pleno, in casu, Mercosul e UNASUL.

A metodologia de trabalho concentrou-se nos aspectos principais estabelecidos para uma pesquisa relativa ao Direito da Integração, devido especialmente ao caráter fragmentado da normativa e institucionalidade constatada nos citados processos integracionistas da região sul-americana. Neste sentido, foram utilizados métodos que permitiram analisar a evolução da dimensão social, especificamente da institucionalidade e participação popular, e sua consequente concretização mediante instrumentos normativos.

Desta forma, o método histórico possibilitou analisar como se deu o desenvolvimento e consolidação do viés social da integração sub-regional mercosulista e da UNASUL. O método dedutivo foi adotado para determinar se e em que medida se prevê mecanismos de participação popular, a partir de sua inclusão no sistema normativo, dando efetividade a tal direito, dado seu caráter civil e político.

\section{A VERTENTE SOCIAL DA INTEGRAÇÃO E A COESÃO SOCIAL}

Sob um ponto de vista sociológico, a temática da integração está direcionada para o estudo da sociedade, considerada como um todo em busca de coesão e, por esta razão, sob um olhar para o indivíduo em um contexto de grupo, coletivo, a ser integrado de forma harmônica, em superação de suas adversidades e diferenças culturais (tais como religiosas, étnicas, linguísticas etc.), em que, quanto maior o grau de identidade e sentimento de pertença, maior a concordância entre os membros desta sociedade, ou grupo, o que, em última análise, determina maior legitimidade das instituições democráticas e, em subsequência, estabilidade e paz sociais.

O viés social nos processos de integração tem se mostrado de grande influência e relevo, ganhando ênfase a partir dos anos 2000, data a partir da qual, inclusive, a União Europeia passou a adotar o lema "Unida na diversidade" como forma de ressaltar a necessidade de se desenvolver um sentido cada vez maior de comunidade entre os indivíduos no âmbito do 
território europeu, a implicar, como esclarecem Prezza e Constantini (1998), um sentimento de pertença e identidade que transcende o individualismo e, segundo o qual, todos se consideram similares (no caso, europeus), agindo de forma independente para a satisfação das suas necessidades coletivas, mediante o expediente da participação comunitária, ou seja, de mobilização e envolvimento dos cidadãos (e população em geral) nos mecanismos de decisão, com impacto em distintos setores (Dalton, Elias, e Wandersman, 2001), criando um âmbito de coesão social, isto é, de sociedade única, harmônica em promoção do bem-comum. A respeito, vale mencionar o disposto na Declaração de Roma (2017), por força do sexagésimo aniversário da Europa

Nestes tempos de mudança, e cientes das preocupações que afligem os nossos
cidadãos, manifestamos a nossa adesão à Agenda de Roma e comprometemo-nos a
trabalhar em prol de: (...) uma Europa social: uma União baseada no crescimento
sustentável que fomente o progresso económico e social, bem como a coesão e a
convergência, salvaguardando ao mesmo tempo a integridade do mercado interno;
uma União que tenha em conta a diversidade dos sistemas nacionais e o papel
fundamental dos parceiros sociais; uma União que promova a igualdade entre
mulheres e homens, bem como os direitos e a igualdade de oportunidades para todos;
uma União que lute contra o desemprego, a discriminaçãa, a exclusão social e a
pobreza; uma União onde os jovens tenham acesso à melhor educação e formação e
possam estudar e encontrar trabalho em todo o continente; uma União que preserve o
nosso património cultural e promova a diversidade cultural

E essa experiência vivenciada por intermédio do sentimento de comunidade (europeia) fornece elementos para um sistema mais profundo de integração social em que, outrossim, seja vista como inserta em tessituras sociais mais amplas, de sorte a afastarem-se ou mitigarem-se também possíveis marginalizações sociais, reservas de mercado ou mesmo situações de xenofobia, em promoção à igualmente necessária integração civil dos estrangeiros no espaço europeu, mediante vias concretas, reais e legítimas de apropriação de informação, autonomia, e empoderamento sociocultural, conforme nos noticia Farias (2016).

Assim, a integração sob o ponto de vista social possibilita, claramente, uma melhora, de modo geral, nas condições de vida da população em território europeu, maxime quanto àqueles que pertençam a estratos sociais menos favorecidos, porquanto viabiliza que os pontos fortes de um indivíduo, ou grupo de indivíduos, sejam ressaltados em uma sinergia concertada (participativa mediante um processo dialógico) em prol da coletividade no seio da almejada coesão decorrente do referido sentimento de comunidade, o que se dá mediante quando os Estados-membros, ou as instituições civis, promovem políticas públicas ou ações (inclusive afirmativas) visando fomentar as habilidades de autonomia pessoal, profissional e social, inserção ocupacional, educação e adequada alimentação, com um consequente 
desenvolvimento sustentável ${ }^{3}$. Em tal direção, Mata Diz, em referência a Molina del Pozo (2002), esclarece

\begin{abstract}
La cohesión económica y social es uno de los objetivos prioritarios de la UE desde hace varios años, ya que el fomento de la cohesión en la Unión favorece un desarrollo armonioso, equilibrado y perdurable de las actividades económicas, crea empleo y contribuye a la protección del medio ambiente, así como a la eliminación de las desigualdades y la promoción de la igualdad entre hombres y mujeres. Con el fin de contribuir al esfuerzo de cohesión económica y social, la Comisión ha creado una serie de instrumentos financieros: los Fondos Estructurales y el Fondo de cohesión, destinados a cofinanciar en los Estados miembros las intervenciones regionales $\mathrm{u}$ horizontales (2009, p. 110). ${ }^{4}$
\end{abstract}

Contudo, faz-se necessário analisar a intrínseca relação entre a dimensão social promovida pelos Estados no âmbito dos processos de integração nos quais os mesmos participam e a participação popular, para que se possa verificar se a sociedade também encontra-se presente no momento de tomada de decisão, haja vista o impacto que os atos adotados no marco da integração pode ter sobre a vida dos cidadãos.

\title{
2.1. A Dimensão Social e a Participação Popular
}

Nesse sentido, Garcia (2007, p. 54) descreve que a dimensão social da integração demanda a atenção em três aspectos: "os efeitos sociais negativos da integração, a participação da sociedade civil no processo e a repartição da dívida social dos países cuja prioridade é atender a pobreza e a exclusão social que afetam grandes setores da população”. Vicente (2015, p.133) ao dissertar sobre as dimensões nos processos de integração regional, em particular, sobre a dimensão social leciona

\begin{abstract}
A dimensão social tem a sociedade como seu esteio e motor através das relações interpessoais, e do desenvolvimento dos espaços da educação, da saúde, da segurança, da cultura, dos direitos coletivos e individuais, da seguridade e da livre circulação das pessoas, da migração, numa forte interação com o Estado, seja na própria esfera estatal, como nas escolas, presídios e hospitais públicos, seja na esfera pública não estatal, como da regulação da convivência em sociedade, dos serviços e mesmo de produção. Sendo a sociedade o locus, por excelência, da existência humana, sofre a convergência e a consequência das ações dos demais sujeitos que anima as demais dimensões.
\end{abstract}

\footnotetext{
${ }^{3}$ A concepção globalizada contemporânea de desenvolvimento sustentável tem por objetivos os traçados pela ONU, cujas metas deverão ser alcançadas até 2030, conforme os pilares dos chamados 5P's (prosperidade, pessoas, planeta, participação e paz - em clara evolução à teoria dos 3P's) constantes da, por isso, dita Agenda 2030.

${ }^{4}$ No original: A coesão económica e social é um dos objetivos prioritários da UE há vários anos, uma vez que a promoção da coesão na União favorece o desenvolvimento harmonioso, equilibrado e duradouro das atividades económicas, cria emprego e contribui para a proteção do meio ambiente, a eliminação das desigualdades e a promoção da igualdade entre homens e mulheres. A fim de contribuir para o esforço de coesão económica e social, a Comissão criou uma série de instrumentos financeiros: os Fundos Estruturais e o Fundo de Coesão, destinados a financiar intervenções regionais ou horizontais nos Estados-Membros.
} 
A integração social implica, de conseguinte, a criação de institutos de concertação, o que pressupõe a existência de diferentes meios democráticos, em distintos níveis de gestão, de participação popular e controle social, tendo-se por base, para tanto, um processo que permita se estabelecer o diálogo entre a população e a Administração Pública, fenômeno este, inclusive, já verificado no complexo bojo da globalização, e no qual se inclui a chamada global governance como forma de sua regulação. Neste contexto, Cravino (1999) ressalta que a legitimidade social do processo aparece como elemento central no sentido de assegurar o êxito integracionista.

Essa circunstância revela, assim, a integração social enquanto um processo complexo, dinâmico e multifatorial, que se imbrica com aspectos jurídicos, políticos, econômicos e culturais de modo geral ${ }^{5}$ (alimentares, étnicos, nacionais, linguísticos, religiosos, tecnológicos etc.), cujo avanço, outrossim, pode encurtar distancias e reduzir a demora na troca de informações (comunicações mais ágeis), trazendo significativa celeridade de dinâmica nas hodiernas relações sociais globalizadas, em evidente facilitação para a circulação de capitais, pessoas, bens e serviços em prol de um comércio internacional mais profícuo. Garcia (2007) ensina que a globalização e as mudanças tecnológicas acarretam uma necessária adaptação da economia e do trabalho que, de conseguinte, induzem a mudanças das políticas sociais.

Em decorrência deste quadro, os processos de integração terminam por acarretar, a depender do sistema normativo e institucional previsto, problemas no campo social a respeito de questões como o pleno emprego, a luta contra o desemprego, as mudanças tecnológicas, os efeitos da organização do trabalho e a exclusão social.

E, justamente por ser um processo complexo, dinâmico e multifatorial, é que a integração permite supor-se que os indivíduos que influencia se verificam reunidos em distintos grupos sociais por um mesmo vínculo (em função de questões comuns, como referido, jurídicas, políticas econômicas e culturais em geral $-v . g$., nacionais, religiosas ou mesmo tecnológicas) e sob um mesmo objetivo ou preceito a ser estrategicamente perseguido para o combate dos seus principais problemas, mediante um esforço coordenado de planejamento supranacional participativo.

\footnotetext{
${ }^{5}$ Resta evidente, de conseguinte, que a integração regional pode ser compreendida por diferentes matizes, como, v. g., objetivos políticos, construções econômicas e reflexos jurídicos, consoante enfatizado em tópicos acima, sendo sempre fortemente permeada pelo fator social, cuja relevância ganha foros de análise individualizada nos estudos contemporâneos, por intermédio da temática envolvida pela dita participação comunitária e global governance.
} 


\section{A INTEGRAÇÃO REGIONAL SUL-AMERICANA: UM ESTUDO DO VIÉS SOCIAL E DA PARTICIPAÇÃO POPULAR NO MERCOSUL E NA UNASUL}

Tal planificação supranacional sócio-integrativa, é de se mencionar, dá-se de forma conjunta e orientada a uma convivência pacífica entre os distintos setores (sociais) que conformam o grupo, sendo a paz social ${ }^{6}$, haurida a partir da coesão para a obtenção dos fins almejados, considerada como a única forma pela qual as partes podem constituir um todo tranquilo e harmônico, embora mantendo a sua individualidade.

$\mathrm{O}$ crescente envolvimento dos diferentes Estados-membros em torno do objetivo comum integracionista, em si, acaba por acarretar a formação de uma maior quantidade de diferentes aparatos institucionais permanentes que, por isso, necessitam ser capazes de respeitar e conviver com as diversidades sociais, evitando, resolvendo ou mitigando os eventuais atritos ao longo do processo, a impor, assim, uma governança regulatória com princípios e regras, como um contrato social entre populações, governos e Estados que estabeleça paz (liberal, legítima e consensual) nas relações integracionistas - uma "paz-como-governança", conforme conceitua Richmond (2010).

Esse contexto exige que os Estados-membros, portanto, convivam com assimetrias estruturais políticas, jurídicas, econômicas e, naturalmente, sociais entre si para a persecução do objetivo comum de integração regional e, com isso, aprimorem também suas instituições, juntamente com as supranacionais, a fim de que possam compensar tais desigualdades a favor de um desenvolvimento coletivo mais equitativo e coeso, sendo, para tanto, aptas promover melhores condições de vida para a população, gerando, assim, empatia e capacidade de emancipação (Richmond, 2010).

Diante dessa realidade, e com o escopo de obter a legitimação de suas ações perante a sociedade civil e de grupos de interesses, os institutos de integração têm incentivado a coesão social com ênfase na concertação, mediante a participação popular e o controle social da atuação dos organismos regionais ao longo do processo (Mata Diz, 2009). Conforme ensina Mata Diz, a contribuição das políticas de coesão para o modelo comunitário ocorre em distintos níveis

\footnotetext{
Las políticas de cohesión contribuyen a consolidar el modelo comunitario en distintos niveles3: i) Económico: reducen disparidades entre países y regiones, permitiendo que la mayor parte de la población contribuya al crecimiento económico. ii) Social: mejoran el acceso al empleo, por medio del fomento a la reconversión y desarrollo y la creación de puestos duraderos. iii) Político: refuerzan la idea de solidaridad comunitaria, creando un marco de oportunidades, tanto adicional como complementario del nacional. Por lo tanto, la interdependencia entre la cohesión social
}

\footnotetext{
${ }^{6}$ Não se olvida da polissemia que a terminologia "coesão social" possui, sendo este o motivo pelo qual apressa-se em esclarecer que neste estudo ora empreendido é adotada sob a acepção estabelecida por Mata Diz (2009).
} 
A integração regional, assim, além de poder ser compreendida mediante diferentes arcabouços teóricos e áreas do conhecimento, também acarreta reflexos em diferentes dimensões, quer políticas, econômicas, jurídicas ou sociais, o que atualmente se dá mediante políticas regulatórias concertadas de coesão social, cada vez mais afinada com os anseios da população europeia em prol de uma paz, dessa forma, legítima e fruto de um consenso defluente de uma governança, na Europa, trabalhada mais especificamente a partir do Livro Branco (2001) e das experiências dele decorrentes.

Estabelecida à realidade em que inserido o fator social no processo de integração (sob o paradigma europeu), passa-se a abordá-lo, ainda que de forma breve, com foco no MERCOSUL e na IIRSA/UNASUL, sob um recorte vocacionado para seus mecanismos concertados de legitimação social, em seu aspecto institucional, de modo a ressaltar o avanço e ganho de relevância desta questão ao longo do desenvolvimento de tais processos integracionista.

\section{A DIMENSÃO SOCIAL NO ÂMBITO DO MERCOSUL}

O Mercado Comum do Cone Sul (MERCOSUL), cujo instrumento inaugural é o Tratado de Assunção para a constituição de um mercado comum, firmado em 26 de março de 1991, não trouxe em seu ato fundacional especificamente o tema social, embora o preâmbulo do tratado, em sua exposição declarativa, mencione que a integração constitua condição fundamental para acelerar seus processos de desenvolvimento econômico com justiça social.

Garcia (2007) salienta que a construção do espaço do MERCOSUL pode ser delineada em duas etapas distintas, ou seja, a primeira compreendida entre a assinatura do Tratado constitutivo, em 1991, até 1994, data esta em que se tem o início da segunda, marcado pela assinatura do Protocolo de Ouro Preto, a qual prossegue até a atualidade. Draibe (2007, p,175) descreve que "a questão social não tomou qualquer institucionalidade própria na primeira etapa de constituição do MERCOSUL".

Todavia, Garcia (2007) menciona que a preocupação com a temática social exsurge, em dezembro de 1991, junto aos Ministros do Trabalho dos Estados-membros na Declaração de Montevidéu. Quando desta declaração, os Ministros se preocuparam com a necessidade de se atender aspectos laborais no MERCOSUL, ressaindo, neste sentido, a proposta de formação 


\section{A INTEGRAÇÃO REGIONAL SUL-AMERICANA: UM ESTUDO DO VIÉS SOCIAL E DA PARTICIPAÇÃO POPULAR NO MERCOSUL E NA UNASUL}

de um subgrupo de trabalho voltado para assuntos laborais e a possibilidade de adoção de uma Carta Social do MERCOSUL.

Ainda, àquela oportunidade, declararam que não somente o Tratado de Assunção desprezou a cidadania e as organizações sindicais, como também os órgãos estatais, particularmente, os competentes em matéria laboral. Por último, a referida declaração também impulsionou a formação do subgrupo de trabalho (SGT 11), agregado a outros já criados pelo Tratado de Assunção, que veio a abordar, particularmente, temas laborais e de seguridade social.

Em relação ao SGT-11, Garcia (2007) acrescenta que um dos primeiros trabalhos desenvolvidos pela Comissão Temática ${ }^{\circ} 08$ - Comissão de princípios, foi a elaboração de uma compilação de 34 (trinta e quatro) Convenções da OIT (Organização Internacional do Trabalho) de ratificação aconselhada aos Estados-membros, o que não obteve aplicação prática. A posteriori, o subgrupo realizou uma reunião em Buenos Aires, ocorrida em 1993, e um seminário para o debate sobre quais os direitos que deveriam ser incluídos na Carta Social do MERCOSUL.

Em 1995, consoante Freitas (2009), o SGT-11 sofreu modificação de nomenclatura, transformando-se no SGT-10 que trata de Relações Trabalhistas, Emprego e Seguridade Social, e com incremento de sua funcionalidade, vez que, enquanto ao grupo anterior cabia, estritamente, a investigação e análise de assuntos propostos pelo GMC, ao SGT 10 coube a possibilidade de definir os temas integrantes das pautas de negociações.

Em 1994, o Protocolo de Ouro Preto, reconheceu expressamente personalidade jurídica de Direito Internacional ao MERCOSUL, delineando a sua estrutura institucional e, ainda que timidamente, inserindo a temática participativa e democrática (embora ainda numa fase de mera união aduaneira incompleta), por meio da incorporação da Comissão Parlamentar Conjunta (CPC) e do Fórum Consultivo Econômico-Social (FCES), o qual, por sua vez, é um órgão de representação dos setores econômicos e sociais, composto por um número igual de integrantes de cada Estado-parte, com funções consultivas ${ }^{7}$ que se manifestam segundo recomendações ao Grupo de Mercado Comum (GMC).

Em junho de 1996, por intermédio da Resolução GMC n 68/1996, foi homologado o Regimento Interno do Fórum Consultivo Econômico-Social (FCES). Posteriormente, a Resolução GMC n 22/2012 revoga a GMC 68/1996, trazendo uma atualização do Regimento

\footnotetext{
${ }^{7}$ Vale mencionar que, para Freitas (2009), o Foro se constituiu sob um caráter consultivo porquanto não dispunha de recursos materiais, econômicos e humanos para realização de seus trabalhos e reuniões.
} 
Interno e a articulação do FCES com outros órgãos do MERCOSUL. Dentre as principais funções atribuídas ao Fórum, tem-se

I - Pronunciar-se, no âmbito de sua competência, emitindo Recomendaç̃̃es, seja por
iniciativa própria ou sobre consultas que, acompanhando informação suficiente,
realizem o GMC e demais órgãos do MERCOSUL. Estas Recomendações podem
referir-se tanto às questões internas do Mercosul quanto à relação deste com outros
países, organismos internacionais e outros processos de integração; II - cooperar
ativamente para promover o progresso econômico e social do Mercosul, tendente a
criação de um mercado comum e sua coesão econômica e social; III - acompanhar,
analisar e avaliar o impacto social e econômico derivado das políticas destinadas ao
processo de integração e as diversas fases de sua implementação, seja a nível setorial,
nacional, regional ou internacional; IV - propor normas e políticas econômicas e
sociais em matéria de integração; V - realizar investigações, estudos, seminários ou
eventos de natureza similar sobre questões econômicas e sociais de relevância para o
Mercosul; VI - estabelecer relações e realizar consultas com instituições nacionais ou
internacionais, públicas ou privadas, quando for conveniente ou necessário para o
cumprimento de seus objetivos; VII - contribuir para uma maior participação da
sociedade no processo de integração regional, promovendo a real integração no
Mercosul e difundindo sua dimensão econômico e social; VIII - Tratar qualquer outra
questão que tenha relação com o processo de integração. (MERCOSUR, 2012)

Não obstante, em 15 de dezembro de 1997, foi aprovado em Montevidéu o Acordo Multilateral de Seguridade Social do MERCOSUL, por ocasião da XIII Reunião do Conselho de Mercado Comum (CMC), mediante a Decisão n 19/1997, o que representou um avanço ao se tratar de garantias para proteção social dos trabalhadores.

No ano seguinte, em 10 de dezembro de 1998, no Rio de Janeiro, foi assinada a Declaração Sócio-laboral do MERCOSUL, pela qual os Estados-membros se comprometiam a adotar uma variedade de princípios em matéria de trabalho, conforme as regras estabelecidas na OIT. Vale ressaltar que, segundo Garcia (2007), esta Declaração de 1998 - devidamente revisada em 2015 revelou-se de significativa importância, à medida que prevê, em seu artigo 20, “1” a "3”, uma instância tripartite de diálogo entre os representantes dos governos, dos empregadores e dos empregados.

Na sequência, em 30 de junho de 2000, ante uma iniciativa do MERCOSUL, Chile e Bolívia proclamaram a Carta de Buenos Aires sobre o Compromisso Social, na qual se reconhece, conforme ressalta Ranzan (2011), a responsabilidade dos Estados para se atingir a equidade social, visto que apenas o crescimento econômico não é condição suficiente para se alcançar a melhoria da qualidade vida.

O próximo passo em matéria laboral no contexto do MERCOSUL, se deu com a instituição de um regramento específico sobre formação profissional (promulgado pela Resolução GMC n 59/2001 quando da XLIV Reunião do GMC - Grupo Mercado Comum 
ocorrida em Montevidéu), de aplicação direta aos Estados-membros (art. 7), sendo devidamente orientado em consonância com políticas empregatícias ligadas à preocupação de que o indivíduo, no âmbito mercosulista, tenha acesso a meios de trabalho digno.

Em 2003, o Conselho de Mercado Comum, com fulcro nos Tratados constitutivos e na própria Declaração GMC n 59/2001, à luz da Recomendação $C M C$ n01/2003, estabeleceu o Repertório de Recomendações Práticas sobre a Formação Profissional, o qual traz em anexo os objetivos que a formação profissional deve perseguir.

De outro lado, sob um ponto de vista político, a Decisão CMC n 49/2004 encerra a concordância em se dar continuidade à formação do Parlamento do MERCOSUL, em substituição à Comissão Parlamentar Conjunta, externando, dessa maneira, ênfase e estímulo à pluralidade sócio-política na região. Sobre o Parlamento, Aguerre e Arboleya (2009) reconhecem que a sua constituição reflete uma inflexão no processo de integração, pois representa uma etapa em que a política se equilibra e nivela junto aos interesses comerciais do bloco, o que ajuda a contrabalancear o protagonismo dos Poderes Executivos, criando um órgão próprio para o debate político e a confrontação de ideias, ajudando a manifestar tanto a pluralidade política regional, como também a criar um espaço para a participação cidadã nos assuntos regionais.

E, no desenvolvimento do processo de integração mercosulista, em dezembro de 2004, com a Decisão CMC n ${ }^{\circ} 45 / 2004$, se estabeleceu a criação do Fundo para a Convergência Estrutural do MERCOSUL - FOCEM, de sorte a, com isso, ter-se um incremento na interconexão estrutural do espaço regional, com evidentes melhoras nas condições de vida e coesão social de sua população.

A subsequente Decisão CMC n ${ }^{\circ}$ 18/2005 repisa que o Fundo está destinado a promover a convergência estrutural, desenvolver a competitividade, promover a coesão social, apoiar o funcionamento da estrutura organizacional e o fortalecimento do processo de integração.

Sobre o FOCEM, Mata Diz, Paula e Secches (2016) lecionam que, em um primeiro momento do seu funcionamento, o fundo foi utilizado para favorecer a interconexão física entre os Estados, priorizando a realidade física existente; no entanto, a partir da Decisão CMC n ${ }^{\circ}$ 01/2010 deixou de se estabelecer qualquer tipo de preferência sobre os programas infraestruturais. De todo modo, sob o ponto de vista institucional no âmbito do MERCOSUL, se reconhece a importância da criação de um fundo voltado para a redução das assimetrias 
regionais e para o desenvolvimento do processo de integração, em aumento da produtividade e coesão social (Mata Diz, Caldas, 2015).

Além das questões laborais e da formação de um fundo de convergência infraestrutural, em 2005, diante da Decisão CMC n 17/2005, foi aprovado o Protocolo de Assunção sobre Direitos Humanos do MERCOSUL, de aplicabilidade imediata nos Estadospartes. Este protocolo vem a ratificar a vigência do Protocolo de Ushuaia e traz no seu art. $3^{\circ}$ as hipóteses de aplicação quando se registrem graves e sistemáticas violações aos direitos humanos e às liberdades fundamentais em uma das Partes, ou em situações de crise institucional, ou durante a vigência de estados de exceção previstos nos ordenamentos constitucionais respectivos. A tal efeito, as demais Partes promoverão as consultas pertinentes entre si e com a Parte afetada.

Ainda em 2005, Gambini (2006) cita a criação da Rede Mercocidades, instituída pela Ata de Fundação das Mercocidades, consoante preconizado na Declaração de Assunção, em 1995. A rede é um instrumento político, permitindo a aproximação dos governos locais com os órgãos decisórios do MERCOSUL, funcionando como um sistema descentralizado de cooperação. Sua principal finalidade é identificar as causas das desigualdades sociais e a difusão da democracia participativa, podendo dela fazer parte todas as cidades dos Estados-membros do MERCOSUL, e seus associados, com o compromisso de respeito à clausula democrática, possuindo alta representatividade, em nível regional, e estimulando a associação de cidades mais afastados do núcleo central da integração, promovendo maior aproximação e coesão do bloco.

Também, em 2005, pela iniciativa da Presidência Pro Tempore do Uruguai, nasce a iniciativa Somos MERCOSUL, representando um ponto importante em relação à preocupação inicial da integração, vez que marcada pela superação de uma óptica focada em aspectos meramente comerciais, em benefício de uma visão voltada para as cadeias de produção, as assimetrias regionais e a implementação de políticas sociais com a participação das sociedades civis. Nas palavras de Aguerre e Arboleya (2009, p.169), a iniciativa Somos MERCOSUL

\footnotetext{
Es un programa de actuación, una plataforma de acción, con una dinámica abierta a la participación de la sociedad civil a través de sus organizaciones representativas. Es un espacio para sumar, una oportunidad para que los actores no tradicionales del Mercosur puedan integrar sus voces y sus voluntades en el proceso de construcción regional. Un territorio de todos, un espacio público regional para promover un debate donde el ciudadano sea protagonista.
}

Em 2006, a Decisão CMC n 04/2006 aprovou a Estratégia MERCOSUL de Crescimento do Emprego. Tal estratégia adotou como bases a geração do emprego como centro 
de articulação de políticas econômicas, sociais trabalhistas e educativas, e o respeito aos princípios e ao próprio direito do trabalho, retomando o papel do Estado na promoção do desenvolvimento com a promoção do emprego digno, a melhoria da distribuição de renda e a redução das desigualdades sociais. Para tanto, busca a articulação de políticas macro e microeconômicas com as trabalhistas, sociais e educativas.

Os desdobramentos da dimensão social, dessa vez, se fizeram presentes por força da chancelaria Argentina que, na reunião de Córdoba, em julho de 2006, organizou o Encontro “MERCOSUL Produtivo e Social”. Esta iniciativa, consoante Aguerre e Arboleya (2009), foi uma primeira experiência que contou com uma numerosa participação de organizações da sociedade civil.

$\mathrm{Na}$ oportunidade, estiverem presentes mais de 400 (quatrocentos) representantes de organizações sociais que debateram sobre o futuro do MERCOSUL e seus setores produtivo e social, bem como a respeito de sociedade e tecnologia, juventude, governos locais e regiões subnacionais.

A reunião de Córdoba foi um importante precedente para, em dezembro de 2006, na cidade de Brasília, a realização da I Cúpula do Social do MERCOSUL. Ao final deste evento, mais de 500 (quinhentos) representantes da sociedade civil aprovaram uma declaração final com recomendações que foram entregues aos presidentes dos Estados-membros do MERCOSUL.

Na Declaração Final (SGPR, 2007), se estabeleceu que os governos devem apoiar e estimular a participação direta das organizações da sociedade civil em todos os Subgrupos de Trabalho e nas Reuniões Especializadas do MERCOSUL, bem como fazer com que sejam criados mecanismos para incorporá-las como observadoras no Grupo Mercado Comum (GMC) e no Conselho Mercado Comum (CMC).

As Cúpulas Sociais do MERCOSUL, segundo Martins e Silva (2011), representam espaços de discussão e formulação de políticas públicas regionais em que participam representantes dos governos, de movimentos sociais e órgãos do MERCOSUL, as quais têm contribuído para a incorporação de novos sujeitos coletivos ao bloco e colaborado com o desenvolvimento da agenda social no processo mercosulista de integração.

Em 2015, as Cúpulas Sociais, mediante a Decisão CMC $n^{\circ} 10 / 2015$, foram transformadas em eventos regulares e oficiais do organograma do MERCOSUL, ao reconhecerse que constituem "um espaço privilegiado para a participação social e uma oportunidade para prestação social de contas do MERCOSUL sobre o estado de avanço do processo de integração 
regional” (MERCOSUR, 2015). Evidencia-se, ainda, que a Unidade de Apoio à Participação Social - UPS, em conformidade com a Decisão CMC n 65/2010, representa um canal institucional de diálogo do bloco de integração com as organizações e movimentos sociais.

Até 2015, cabe registrar, foram realizadas 18 (dezoito) edições da Cúpula Social, a saber: Brasília (2006), Assunção e Montevidéu (2007), Tucumã e Salvador (2008), Assunção e Montevidéu (2009), Resistencia/Isla del Cerrito e Foz do Iguaçu (2010), Assunção e Montevidéu (2011), Brasília e Mendoza (2012), Montevidéu (2013), Caracas e Paraná-Entre Rios (2014) e Brasília (2015).

Finalmente, vale ressaltar que o tema do desenvolvimento da dimensão social no MERCOSUL é repisado também pela Decisão CMC 03/2007, com a criação do Instituto Social do MERCOSUL - ISM, no intuito de "fortalecer o processo de integração e promover o desenvolvimento humano integral" (MERCOSUR, 2007). O instituto, dessa forma, nasce como uma instância de pesquisa no campo das políticas sociais com os objetivos de consolidar a dimensão social como um eixo fundamental do bloco, superar as assimetrias, sistematizar e atualizar os indicadores sociais regionais, promover mecanismos de cooperação horizontal, recompilar e intercambiar boas práticas em matéria social e identificar fontes de financiamento.

\section{A IIRSA E A NECESSIDADE DE CRIAR UM MARCO SOCIAL PARA A INTEGRAÇÃO SUL-AMERICANA}

A IIRSA nasceu da inciativa do governo pátrio quando da comemoração dos 500 (quinhentos) anos do descobrimento do Brasil. Assim, entre os dias 31 de agosto e 01 de setembro de 2000, foi promovida a primeira Reunião de Cúpula da América do Sul, culminando, neste encontro presidencial, com o lançamento da Iniciativa da Infraestrutura Regional da América do Sul (IIRSA). À oportunidade, os mandatários dos 12 (doze) países sulamericanos trataram de diversos temas de interesse regional, ulteriormente inseridos no Comunicado de Brasília, o qual consubstancia o instrumento fundante da iniciativa.

O Comunicado de Brasília, não obstante tenha trazido uma pluralidade de temas, não estabeleceu uma disposição especifica sobre a questão social, que apenas é mencionada de forma esparsa em diversos pontos do documento. Todavia, diante da notória problemática de interconexão infraestrutural regional, reservou-se uma parte especial para ter-se uma abordagem a respeito do seu desenvolvimento de infraestrutura, inclusive com vista ao incremento da coesão social regional. 
Pode-se dizer que o processo institucional de integração regional não parou após o Comunicado de Brasília. Ao contrário, foram realizadas diversas reuniões de presidentes sulamericanos que acarretaram na criação da UNASUL, com a consequente incorporação da IIRSA na qualidade de Foro Técnico do COSIPLAN.

Em 2004, na cidade de Cusco (Peru), ocorreu a Terceira Reunião de Presidentes da América do Sul, quando se estabeleceu a criação da Comunidade Sul-Americana de Nações CSN, considerada o antecedente institucional da UNASUL. Segundo Nery (2016, p. 68), a CSN foi concebida em torno de três eixos: "a concertação e coordenação de políticas exteriores; a convergência entre MERCOSUL, CAN, Chile, Guiana e Suriname; e a integração física por meio da IIRSA".

Entre os dias 29 e 30 de setembro de 2005, em Brasília, foi celebrada a Primeira Reunião de Chefes de Estado da Comunidade Sul-Americana de Nações. Na época, se aprovou uma institucionalidade mínima, bem como foram estabelecidas áreas prioritárias para o novo organismo: o diálogo político, a integração física, o meio ambiente, a integração energética, os mecanismos financeiros sul-americanos, as assimetrias, a coesão social, a inclusão social, a justiça social e as telecomunicações.

Na segunda Cúpula da Comunidade Sul-americana de Nações - CSN, ocorrida em Cochabamba, em 2006, foram definidos os objetivos e princípios a serem por si perseguidos. É importante ressaltar que a construção do novo bloco, conforme descrito na Declaração de Cochabamba, pretendeu envolver os aspectos políticos, social, econômico, financeiro, ambiental e de infraestrutura. Ademais, o documento valoriza a construção de uma cidadania sul-americana e, em matéria social, prevê a criação de mecanismos de diálogo entre as instituições da CSN e a sociedade civil, que permitam maior participação na formulação das políticas de integração sul-americana.

Em 2007, entre os dias 16 e 17 de abril de 2007, ocorreu em Isla Margarita, a Primeira Cúpula Energética Sul-americana. Neste encontro, além do tema energético, os presidentes sulamericanos decidiram institucionalizar um novo bloco regional que passaria a se chamar de União das Nações Sul-americanas (UNASUL), em substituição à Comunidade Sul-americana de Nações - CSN.

A Primeira Reunião da UNASUL ocorreu no dia 23 de maio de 2008, em Brasília, quando os mandatários trataram da aprovação do texto do Tratado Constitutivo da UNASUL, que veio a entrar em vigor de março de 2011. 
A UNASUL, de acordo com o seu Tratado Constitutivo, nasceu dotada de personalidade jurídica internacional, com sede permanente de sua Secretaria Geral em Quito, no Equador. De acordo com Nery (2016), o texto do tratado foi idealizado sob inspiração do Comunicado de Brasília e das Declarações de Cusco e Cochabamba, nele salientando-se a determinação de construção de uma identidade e cidadania sul-americanas, em um espaço de integração nas esferas política, econômica, social, ambiental e de infraestrutura.

A UNASUL, no art. $2^{\circ}$ do seu Tratado constitutivo, traz os objetivos gerais a serem perseguidos no espaço sul-americano de integração. Dentre a pluralidade de objetivos, o tema social novamente se repete como nas declarações anteriores da CSN, ou seja, segundo uma participação cidadã, mediante mecanismos de integração e diálogo, entre a UNASUL e os atores sociais, que sejam voltados para a formulação de políticas regionais sul-americanas, bem como para a consolidação de uma identidade sul-americana.

A partir da formação da UNASUL, diversos mecanismos foram desenvolvidos no âmbito deste novo organismo. Em 2011, a IIRSA foi-lhe incorporada como parte do Foro Técnico do Conselho Sul-Americano de Infraestrutura e Planejamento (COSIPLAN). Em matéria social, com o escopo de garantir e promover a plena participação dos atores sociais na formulação de políticas de integração sul-americana, foi criado, em 2013, o Foro de Participação Cidadã (FPC).

Na Primeira reunião do Foro de Participação Cidadã, ocorrida em 2015, os trabalhos se organizaram em torno de três mesas: i) aprofundamento do processo de integração sulamericana desde a participação cidadã; ii) conformação do Foro de Participação Cidadã, estipulando-se lineamentos gerais de trabalho interno; e, iii) agendas Prioritárias do Foro de Participação Cidadã, com a criação de um Plano de Trabalho.

Entre os principais resultados da Primeira Reunião do Foro figuram a identificação dos eixos temáticos e as políticas a serem impulsionadas pelos Estados. Também se ressaltam: a vocação para o avanço de temas como o reconhecimento de qualificações acadêmicas nos Estados da UNASUL; a criação da Universidade latino-americana; o impulso a políticas públicas de saúde intercultural; respeito à diversidade sexual; erradicação da violência contra as mulheres; busca da soberania científica e tecnológica para superação do fosso digital e descolonização do ciberespaço, e a promoção de leis de mobilidade humana; defesa dos recursos naturais; plena participação dos povos indígenas; e uma série de ações para fortalecer e assegurar a participação e mobilização da sociedade civil de forma eficaz, entre outros. 


\title{
A INTEGRAÇÃO REGIONAL SUL-AMERICANA: UM ESTUDO DO VIÉS SOCIAL E DA PARTICIPAÇÃO POPULAR NO MERCOSUL E NA UNASUL
}

Já na Segunda Reunião do Foro, realizada em Quito em novembro de 2016, os principais temas tratados foram: o respeito à democracia, aos direitos humanos e a promoção da paz pelos Estados participantes; ii) a necessidade de estabelecer um marco normativo internacional para as empresas transnacionais; iii) o apoio aos processos de descolonização ainda vigentes, como é o caso do Saara Ocidental e, iv) expressa manifestação em relação aos acordos de paz na Colômbia.

Uma questão interessante, digna de nota, é a menção expressa à proposta feita no âmbito das Organizações das Nações Unidas (ONU) relativa à Resolução 26/9 de 26 de junho de 2014 da lavra do Conselho de Direitos Humanos da ONU. Tal Resolução estabelece um Tratado vinculante sobre a atuação global das empresas transnacionais e, onde se menciona a necessidade de criar um marco regulatório que disponha sobre a responsabilidade de tais empresas e a respectiva proteção dos direitos humanos. Textualmente, assim sublinha a Declaração Final (2016, p. 2) exarada do Foro

\begin{abstract}
Preocupado com a relação assimétrica entre corporações transnacionais, empresas comerciais e Estados sul-americanos, o que gera sérias implicações para o respeito, proteção e garantia dos Direitos Humanos, ao permitir o desenvolvimento de atividades transfronteiriças sem o controle dos Estados nacionais, diante da lacuna jurídica, no âmbito da Resolução 26/9 de 26 de junho de 2014 do Conselho de Direitos Humanos das Nações Unidas, apoiamos a elaboração do instrumento jurídico internacional vinculante e incentivamos a participação dos Estados sul-americanos para participar do processo de geração desses instrumentos. ${ }^{8}$
\end{abstract}

Finalmente, na Terceira Reunião do Foro, realizada em novembro de 2017, estabeleceu-se como tema principal a proteção da velhice, da infância e das pessoas portadoras de necessidades especiais, instando os Estados a promover políticas públicas que venham a assegurar a igualdade de tratamento para todas as pessoas.

Contudo, vale ressaltar que o Foro não tem participação direta no processo de tomada de decisão quanto à forma de financiamento dos projetos de infraestrutura, já que nada diz a respeito da gestão do financiamento de outros órgãos da UNASUL, o que levanta questionamentos acerca de sua legitimidade social. Como o FPC intitula-se como principal órgão de participação cidadã, seria de se esperar que, caso houvesse uma voz social efetiva no

\footnotetext{
${ }^{8}$ No original: Preocupados por la relación asimétrica entre las empresas transnacionales, empresas de negocios y Estados Suramericanos, que genera graves implicaciones en el respeto, protección y garantía de los Derechos Humanos, al permitir el desarrollo de actividades transfronterizas sin rendición de cuentas a los Estados nacionales y ante el vacío legal, en el marco de la Resolución 26/9 de junio 26 del 2014 del Consejo de Derechos Humanos de las Naciones Unidas, respaldamos la elaboración del instrumento jurídico internacional vinculante y exhortamos la participación a los Estados Suramericanos a participar en el proceso de generación de dichos instrumentos.
} 
processo de integração física, muitos projetos não seriam aprovados da forma como o foram (Mata Diz; Secches; Paula, 2016).

Outra crítica pertinente refere-se ao fato de que o Foro foi criado um ano após a aprovação dos projetos no Plano Estratégico, e isso poderia ser uma tentativa de legitimação tardia. Ainda que o objetivo de participar na formulação das políticas de integração já tenha sido prejudicado, o FPC ainda tem o poder de participar nas diversas etapas de implantação de projetos de integração, além de poder realizar investigações e assessorar o Conselho de Chefes do Estado e os demais órgãos da UNASUL, como a IIRSA. O artigo 5 da Decisão n. 7/12 instrui que outras instâncias da UNASUL, como a IIRSA, incorporem nos planos de ação a realização de eventos de diálogo com representante do FPC.

De fato, foi encontrado um documento que reforça tal compromisso durante a VIII reunião do COSIPLAN ocorrida em 2015, e, paralelamente o site da UNASUL, por sua vez, evidencia três encontros do Secretário Geral da UNASUL com representantes do FPC. Contudo, não se sabe o conteúdo do que foi debatido, dada a completa ausência de informações e documentos atinentes a tais encontros, o que reforça a necessidade de transparência no processo decisório.

\section{CONCLUSÃO}

$\mathrm{Na}$ América do Sul, em especial, quando se analisam os processos de integração existentes verifica-se uma lacuna importante no que tange ao estudo da dimensão social de tais processos, ainda identificados como meros espaços para incrementar o intercâmbio comercial. Contudo, o viés social não pode ser considerado como um aspecto de menor relevância, dado que a produção normativa e a estrutura institucional, em grande medida, podem resultar em impactos sobre a vida da população dos Estados participantes.

A questão da dimensão social, a partir da participação cidadã sobre o processo de tomada de decisão, pode e deve ser instigada, especialmente quando se considera a fragilidade dos valores democráticos na região sul-americana, tal e como noticiado frequentemente nos meios acadêmicos e de comunicação.

A inclusão de meios de participação popular e controle social, mediante a criação de instâncias próprias no âmbito dos processos integracionistas, notadamente, in casu, no Mercosul e na UNASUL representam um instrumento de legitimidade necessária para que as decisões tomadas pelas instituições decisórias possam, efetivamente, concretizar os valores 


\section{A INTEGRAÇÃO REGIONAL SUL-AMERICANA: UM ESTUDO DO VIÉS SOCIAL E DA PARTICIPAÇÃO POPULAR NO MERCOSUL E NA UNASUL}

democráticos, o respeito aos direitos humanos e, especialmente, a consolidação do ideário de uma sociedade civil coesa.

Sem dúvida, o desenvolvimento da democracia e a conseguinte participação cidadã, portanto, está intimamente ligada à busca de maior igualdade social, à luta eficaz contra a pobreza e à expansão dos direitos dos cidadãos.

Neste sentido, a análise realizada no presente artigo buscou demonstrar quais seriam as instâncias de participação, e os meios de expressão nela configuradas, para que o Mercosul e a UNASUL possam ser considerados como processos voltados para o fortalecimento da dimensão social, participativa e dialogada.

Finalmente, os sistemas de integração podem ser a fórmula capaz de garantir uma verdadeira democracia, proporcionando um grau de intercâmbio permanente e uma interação entre a sociedade civil e as instituições voltadas para processo de tomada de decisão. Os processos de integração podem, além disso, fornecer a troca contínua de experiências que venham, realmente, efetivar a democracia participativa nos Estados sul-americanos. A desigualdade e a exclusão social vivenciadas, em maior ou menor grau, por todos os países da região podem ser consideradas como elemento a propiciar uma necessária inclusão da participação cidadã. A atuação da sociedade civil constitui, indubitavelmente, a força-motriz destinada ao fortalecimento, à autonomia e a complementaridade que deve estar presente nas relações entre os Estados e as sociedades que o compõem. E não há melhor mecanismo para promover esta complementaridade que os processos de integração, em suas mais variadas formas.

\section{BIBLIOGRAFIA}

AGUERRE, Maria Júlia; ARBOLEYA, Ignácio. Estratégias para un MERCOSUR ciudadano. In: CAETANO, Gerardo. La reforma institucional del MERCOSUR: del diagnóstico a las propuestas. Centro de Información para la integración regional: Montevideo, 2009. Disponível em: <http://www.inmercociudades.org/download/ciudadania-regional/20.pdf>. Acesso em: 01 de julho de 2016.

CRAVINO, Gonzalez. Globalización, integración y cohesión social: El caso del Mercosur. In: DI FILIPPO, Armando; FRANCO, Rolando (org.). Las dimensiones sociales de la integración regional en América Latina. Santiago: Cepal, 1999. Disponível em: <http://repositorio.cepal.org/bitstream/handle/11362/2190/S9860431_es.pdf;jsessionid=608A 0FA85C4D6CE0BDCAF7DB6FD71D39? sequence=1>. Acesso em: 17 nov. 2016.

DALTON, James H.; ELIAS, Maurice J.; WANDERSAMAN, Abraham. Community psychology: linking individual and communities. Wadsworth: Thomson Learning, 2001, p. 186-217. 
Foro de Participación ciudadana UNASUL. Declaración Final. Quito, 2016, disponível em https://www.integracion-lac.info/en/node/37960, acesso em 12.10.17

DRAIBE, Sônia Miriam. Coesão social e integração regional: a agenda social do MERCOSUL e os grandes desafios das políticas sociais integradas. Cad. Saúde Pública, v. 23, supl. 2, p. 174-S183, 2007.

Disponível

em $<$ http://www.scielo.br/scielo.php?script=sci_arttext\&pid=S0102-

311X2007001400007\&lng=en\&nrm=iso>. Acesso em 12 de julho de 2016. http://dx.doi.org/10.1590/S0102-311X2007001400007.

FARIAS, Maria Giovanna Guedes. A informação como potencializadora da autonomia e da integração social. Transinformação [online], vol.28, n.3, 2016, p.323-336.

FREITAS, Valter de Almeida. A circulação do trabalho no MERCOSUL e na União Europeia. EDUNISC: Santa Cruz do Sul, 2009.

GAMBINI, Priscila Truviz. Rede MERCOCIDADES: a legitimidade da ação internacional de governos locais brasileiros para o fortalecimento da integração regional no MERCOSUL. In: XV Congresso do CONPEDI. Manaus, 2006.

GARCIA, Valeria Paola Vetuschi. A dimensão social dos processos de integração regional: as estratégias do MERCOSUL e da União Europeia. Dissertação de Mestrado (Mestrado em Integração Latino-americana). Universidade Federal de Santa Maria. Santa Maria, RS. p.107. 2007.

MARTINS, José Renato Vieira; SILVA, Carolina Albuquerque. Políticas Sociais e Participação Social: A constituição de uma esfera pública regional no MERCOSUL. In: Boletim de Economia e Política Internacional, n. 05, jan/mar. IPEA, 2011. Disponível em: http://www.ipea.gov.br/portal/index.php?option=com_content $\&$ view=article $\&$ id=7475\&Itemi $\mathrm{d}=4$. Acesso 20 de dezembro de 2016.

MATA DIZ, Jamile Bergamaschine. Un enfoque distinto de la integración regional: la cohesión social en la Unión Europea y América Latina. NEJ - Novos Estudos Jurídicos, v. 14, n. 1, jan/abr 2009, p. 107126. Disponível em: < https://siaiweb06.univali.br/seer/index.php/nej/article/view/1625/1331〉. Acesso em 17 de setembro de 2017.

MATA DIZ, Jamile Bergamaschine; CALDAS, Roberto Correia da Silva Gomes. A licitação no âmbito do MERCOSUL e os recursos do Fundo de Convergência Estrutural (FOCEM): análise sistêmica das normas regionais e nacionais. In: KNOERR, Fernando Gustavo; CARDOSO, Henrique Ribeiro; MENDONÇA, Maria Lírida Calou de Araújo e (Coord.). Direito e Administração Pública. Florianópolis: CONPEDI, $1^{\text {a }}$ ed., 2015, p. 90-120. Disponível em: <http://www.conpedi.org.br/publicacoes/c178h0tg/64czmib9/ R0L12vU761V0Gm5V.pdf>.

MATA DIZ, Jamile Bergamaschine; PAULA, Mariana Porto de; SECCHES, Daniela Vieira. Os atores interestatais no desenvolvimento regional e a participação social: a atuação dos grupos argentinos nos projetos de infraestrutura da IIRSA e do FOCEM. In: Revista Direito GV. v. 12, n. 3, set-dez 2016, p. 776-809. Disponível em: http://www.scielo.br/pdf/rdgv/v12n3/1808-2432-rdgv-12-03-0776.pdf. Acesso em 17 de 
setembro de 2017.

MERCOSUR. Criação do Instituto Social do MERCOSUL - ISM. Decisão CMC n 03/2007. Disponível em: http://www.mercosur.int/innovaportal/v/634/2/innova.front/decisiones-2007. Acesso em 01 de julho de 2016.

MERCOSUR. Resolução GMC n ${ }^{\circ}$ 22/2012. Regimento Interno do Foro Consultivo Econômico-Social do MERCOSUL. Disponível em http://www.mercosur.int/innovaportal/v/4151/2/innova.front/2012. Acesso de 11 de novembro de 2016.

MERCOSUR. Decisão CMC $n^{\circ}$ 10/2015. Organizações e Movimentos Sociais do MERCOSUL. 2015.2 Disponível em: <http://gd.mercosur.int/SAM\%5CGestDoc\%5CPubWeb.nsf/976DC1EF7535D945032582D8 005BD9BE/\$File/DEC_010-2015_PT_OrganizacoeseMovSociais.pdf $>$. Acesso em: 12 de novembro de 2016.

MOLINA DEL POZO, Carlos Francisco. Manual de Derecho de la Comunidad Europea. Ed. Dijusa: Madrid, 4. ed., 2002.

NERY, Tiago. UNASUL: a dimensão política do novo regionalismo sul-americano. Cad. CRH, Salvador, v. 29, n. 3, p. 59-75, $2016 . \quad$ Disponível em $<$ http://www.scielo.br/scielo.php?script=sci_arttext\&pid=S010349792016000600059\&lng=en\&nrm=iso>. Acesso em 15 de janeiro de 2017. http://dx.doi.org/10.1590/S0103-49792016000400005.

PORTO, Manuel Carlos Lopes; FLÔRES JR., Renato Galvão. Teoria e políticas de integração na União Europeia e no Mercosul. Rio de Janeiro: FGV Editora, 2006.

PREZZA, Miretta; CONSTANTINI, Stefano. Sense of community and live satisfaction: Investigation in three different territorial contexts. Journal of Community \& Applied Social Psychology, ano 8, vol. 3, 1998, p. 181-194.

RANZAN, Eduardo Antônio Campos. O MERCOSUL no século XXI: Combatendo assimetrias e ampliando o diálogo. Monografia (Bacharelado em Relações Internacionais). Universidade Federal do Rio Grande do Sul, RS. 2011, p.90.

RICHMOND, Oliver P. Para Além da Paz Liberal? Respostas ao "Retrocesso". Trad. de Victor Coutinho Lages. Contexto Internacional, vol. 32, n. 2, p. 297-332, julho/dezembro 2010

SGPR. Secretaria Geral da Presidência da República. Declaração Final da I Cúpula Social do MERCOSUL, $2007 . \quad$ Disponível em: <http://www.secretariadegoverno.gov.br/.arquivos/portfinal>. Acesso em: 12 de dezembro de 2016.

UNIÃO EUROPEIA. Declaração de Roma, de 25 de março de 2017. Disponível em: <https://webcache.googleusercontent.com/search?q=cache:1SxTFdle0T0J:https://europa.eu/e uropean-union/file/22756/download_pt\%3Ftoken\%3DIzxiHaS-+\&cd=2\&hl=pt BR\&ct $=$ clnk\&gl=br $>$. Acesso em: 01 de abril de 2017. 
UNIÃO EUROPEIA. Livro Branco da Comissão Europeia “A Governança Europeia”, de 25 de julho de 2001 - COM (2001). Disponível em <http://eur-lex.europa.eu/legalcontent/PT/TXT/HTML/?uri=CELEX:52001DC0428\&qid=14 27890581685\&from=EN>. Acesso em 01 de abril de 2015.

VICENTE, Francisco Jorge. Dimensão social em processos de integração regional: aspectos teóricos e o caso do MERCOSUL. 2015. 246 p. Dissertação (Mestrado em Estudos Estratégicos Regionais). Faculdade de Ciências Econômicas. Universidade Federal do Rio Grande do Sul, Porto Alegre. Disponível em: 〈https://www.lume.ufrgs.br/handle/10183/132920>. Acesso em: 06 de junho de 2016. 